\title{
THE HEPARIN INDUCED THROMBOCYTOPENIA IN CARDIAC SURGERY PATIENTS
}

\author{
Shakila Khadim, Nuzhat Salamat*, Saleem Ahmed Khan, Kifayatullah*, Nasiruddin***, Muhammad Abdul Naeem \\ Army Medical College/National University of Medical Sciences (NUMS) Rawalpindi Pakistan, *Armed Forces Institute of Transfusion/ \\ National University of Medical Sciences (NUMS) Rawalpindi Pakistan, **Armed Forces Institute of Cardiology (AFIC/NIHD)/National \\ University of Medical Sciences (NUMS) Rawalpindi Pakistan, ${ }^{* * *}$ Combined Military Hospital Lahore/National University of Medical Sciences
} (NUMS) Pakistan

\begin{abstract}
Objective: Combination of '4Ts' clinical scoring system and Particle gel immunoassay to determine the frequency of heparin-induced thrombocytopenia during heparin treatment in cardiac surgery patients.

Study Design: Prospective observational study.

Place and Duration of Study: This study was conducted in the Pathology Department, Army Medical College in collaboration with Armed Forced Institute of Cardiology and Armed Forced Institute of Transfusion, Rawalpindi, from Jan 2019 to Dec 2019.

Methodology: A total of 115 suspected cases of heparin-induced thrombocytopenia irrespective of age and gender were included in the study. A clinical scoring system the '4Ts' was used for the classification of patients based on probability into three groups such as low, intermediate, and high probability groups. For the detection of antibodies against heparin/platelet factor 4 complexes, the Particle gel immunoassay was used.

Results: There were 39 (33.9\%) females and 76 (66.1\%) males, the age range of 20 to $86 \pm 12.9$ years. Among the low probability group, there was no positive result, $2(2.3 \%)$ patients showed positive serological evidence in the intermediate probability group. In the high probability group, $4(23.5 \%)$ patients showed positive results with the chosen assay.

Conclusion: Heparin-induced thrombocytopenia was found an overall 5.2\% of patients undergoing cardiac surgery receiving unfractionated heparin. A combination of ' $4 \mathrm{Ts}$ ' pretest clinical scoring systems followed by PaGIA constitutes a simple strategy to screen for heparin-induced thrombocytopenia in suspected patients. This will avoid serious complications if the detection is not delayed.
\end{abstract}

Keywords: Heparin-induced thrombocytopenia (HIT), PaGIA and 4Ts.

This is an Open Access article distributed under the terms of the Creative Commons Attribution License (http://creativecommons.org/licenses/by/4.0), which permits unrestricted use, distribution, and reproduction in any medium, provided the original work is properly cited.

\section{INTRODUCTION}

Heparin-induced thrombocytopenia (HIT) is an immune-mediated complication of un-fractionated heparin (UFH) or low molecular weight heparin $(\mathrm{LMWH})$ and can result in dangerous thromboembolismand even death ${ }^{1}$. Immune HIT presents on 5-14 days after administration of heparin resulting in the development of antibodies (IgG) and a $50 \%$ or more decline inplatelet count than the actual baselinevalue ${ }^{2}$. In accordance with population, type and time interval of heparin exposure, the prevalence of HIT varies from 0.5$5 \%{ }^{3}$.

The diagnosis of HIT is based on clinical manifestations and the identification of HIT

Correspondence: Dr Shakila Khadim, Pathology Department, Army Medical College Rawalpindi Pakistan

Received: 24 Mar 2020; revised received: 10 Sep 2020; accepted: 16 Sep 2020 antibodies relative to heparin exposure. The main diagnostic challenge is to differentiate thecause of thrombocytopenia post-operatively from other causes that are not associated with HIT having positive anti PF4 antibodies 4 .

The '4Ts' scoring system has been devised by Warkentin and Hedlli for calculating the pretest probability of HIT5 . A definite diagnosis of HIT cannot be made in the absence of laboratory demonstration of heparin platelet factor 4 (H-PF4) antibodies ${ }^{6}$. Currently, the laboratory testing for HIT falls into two categories, immunological (antigen) and functional (platelet activation) assays. Immunoassay (particle gel) detects the initial immune response by determining the circulating anti-PF4 / heparin antibodies without taking into account, their ability to activate platelets whereas evidence of platelet activation by heparin 
induced thrombocytopenia antibodies are detected with functional assays ${ }^{4}$. Functional assays are technically more challenging, require specialized reagents, methods and can need reference laboratory assistance ${ }^{7}$.

The 4Ts clinical scoring system can be combined with the particle gel assay for heparin antibody to strengthen the post-test probability of HITT his constitutes an efficient strategy for application in suspected HIT patients to assist timely management including discontinuing all types of heparin and substituting an alternative anticoagulant ${ }^{8}$.

There are limited reports of the prevalence of HIT in post-cardiac surgical patients from our region, therefore our study aims to evaluate HIT after heparin exposure in patients by using clinical '4Ts' scoring system and particle gel assay for detection of heparin/PF4 antibodies.

\section{METHODOLOGY}

A prospective observational study conduc-

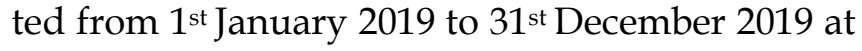

Forced Institute of Transfusion Rawalpindi after approval from Institutional Review Board and ethics committee (IERB/9/3/2020). The sample size of 115 was calculated with the help of the WHO calculator. The anticipated population was $7 \%$ out of 115 suspected HIT according to a previous study of Pakistan in the year 20099. The sampling technique was non-probability purposive sampling. Informed consent was taken from all the participants and caretaker of unconscious patients. Cardiac surgery patients on heparin therapy for anticoagulation, irrespective of age, and gender of the patient were included in the study. Patients with low platelet count due to confirmed causes as well as incomplete preoperative workup records of heparin and platelet counts were excluded.

The type and dosage of heparin before and after cardiac surgery was noted. Patients were classified based on the pretest '4Ts' clinical scoring system named into three groups low probability, intermediate probability and high probability group 10 shown in table-I.

Table-I: 4T Score for heparin induced thrombocytopenia ${ }^{24}$.

\begin{tabular}{|c|c|c|c|}
\hline & 0 & 1 & 2 \\
\hline Platelet count fall & $\begin{array}{l}\text { No points if the dec-line } \\
\text { in platelet count is less } \\
\text { than } 30 \% \text { or platelet } \\
\text { nadir is }<10 \times 10^{9} / \text { liter. }\end{array}$ & $\begin{array}{c}1 \text { point if the platelet count } \\
\text { decreases between } 30-50 \% \\
\text { or the nadir is } 10-19 x \\
10^{9} / \text { liter }\end{array}$ & $\begin{array}{l}2 \text { points for more than } 50 \% \\
\text { fall in platelet count and } \\
\text { lowest count (nadir) is }>20 \mathrm{x} \\
10^{9} / \text { liter }\end{array}$ \\
\hline Timing & & $\begin{array}{l}\text { I point if the platelet count } \\
\text { declines after } 10 \text { th day of } \\
\text { heparin treatment. If anyone } \\
\text { has received heparin with in } \\
\text { recent past } 30-100 \text { days and } \\
\text { then has a fall in platelet } \\
\text { count with in a day of re } \\
\text { exposure to heparin. }\end{array}$ & $\begin{array}{l}2 \text { points for the platelet } \\
\text { count decreases between } \\
\text { days } 5-10 \text { after starting the } \\
\text { heparin. If someone has } \\
\text { received the heparin within } \\
\text { last } 30 \text { days and then has } \\
\text { decline in platelet count } \\
\text { with in a day of re exposure } \\
\text { to drug heparin. }\end{array}$ \\
\hline Thrombosis & $\begin{array}{l}\text { If there are no symp- } \\
\text { toms than no points. }\end{array}$ & $\begin{array}{l}1 \text { point if there is prog- } \\
\text { ressive or recurrent or silent } \\
\text { thrombosis and also for red } \\
\text { skin lesions. }\end{array}$ & $\begin{array}{l}\text { For new skin necrosis, new } \\
\text { proven thrombosis or syste- } \\
\text { matic reaction there is } 2 \\
\text { points. }\end{array}$ \\
\hline $\begin{array}{l}\text { Alternative causes } \\
\text { for platelet count fall }\end{array}$ & $\begin{array}{l}\text { If there is definite other } \\
\text { cause than there is no } \\
\text { points }\end{array}$ & $\begin{array}{l}1 \text { point for the possible } \\
\text { alternative cause. }\end{array}$ & $\begin{array}{l}\text { If there is no other cause } \\
\text { than there is } 2 \text { points. }\end{array}$ \\
\hline
\end{tabular}

Army Medical College in collaboration with Armed Forced Institute of Cardiology and Armed
For detection of H-PF4 antibodies, a particle gel immunoassay known as ID-Heparin/PF4 
antibody test (ID-HPF4) (BIO-RAD, Diamed SA, Cressier sur Morat, Switzerland) was used as per instruction of the manufacturer. About $3 \mathrm{ml}$ of blood sample was drawn in plain gel tube for obtaining serum after clotting at $37^{\circ} \mathrm{C}$ reaction due to fibrin residue. Ten (10) $\mu \mathrm{l}$ of serum was placed in the upper reaction chamber of micro-tube of ID-PaGIA/HPF4 Ab test. From the suspension of PaGIA/ HPF4 particles, a $50 \mu l$ solution was pipetted into a gel matrix. The incubation of ID-Card at room temperature for 5 minutes was done. After centrifugation for 10 minutes, the result was read and recorded. For validation of the result, positive and negative controls present in the IDPaGIA heparin/antibody test kit were included with each series of tests.

All of 115 patients were tested for H.PF4 antibodies before and after surgery. Before surgery, all the plasma samples were found to be negative for HIT antibodies.

Sysmex KX-21 Automatic hematology analyzer with appropriate quality control was used to obtain complete blood counts for platelet counts. Thrombocytopenia was rechecked manually with the help of Leishman stained peripheral film. Statistical package for social sciences (SPSS 22) was used for the statistical evaluation of data. Frequency and percentage for qualitative variables, the mean and standard deviation for quantitative variables. A non-parametric test (Wilcoxon signed-rank) was used to express the change in platelet count before and after heparin treatment in cardiac surgery. A comparison among groups was made using the Chi-square test.

\section{RESULTS}

A total of 115 patients undergoing cardiac surgeries and receiving heparin therapy were included in this study. The various cardiac surgeries performed on the patients are shown in tableII and there was no statistically significant change in the incidence of HIT reported in our study due to the nature of intervention performed. Out of 115 patients, 39 were females and 76 were males and their ages ranged from 20 to $86 \pm 12.9$ years.
The laboratory investigation before surgery showed the platelet count mean $243.10 \times 10^{9} / \mathrm{L}( \pm$ $48.35)$ whereas platelet count after surgery on day 5 is $110.88 \times 10^{9} / \mathrm{L}( \pm 39.67)$.

When the test was performed on day 5 to 8 post-surgically only $6(5.2 \%)$ patients show positivity of heparin platelet factor 4 antibodies and $95(94.8 \%)$ patients show negativity in results of having H.PF4 antibodies. These 6 patients had more than $50 \%$ drop in platelet count from their baseline. The number of patients testing positive for antibodies against Heparin/Platelet factor 4 complex in each group was shown in table-II.

Table-II Characteristics of patients present in study.

\begin{tabular}{l|c}
\hline Platelet Counts & $\begin{array}{c}243.10 \times 10^{9} / \mathrm{L} \\
( \pm 48.35)\end{array}$ \\
\hline $\begin{array}{l}\text { Platelet counts before surgery } \\
\text { (mean) }\end{array}$ & $\begin{array}{c}110.88 \times 10^{9} / \mathrm{L} \\
( \pm 39.67)\end{array}$ \\
\hline \begin{tabular}{l} 
Platelet counts after surgery day 5 to 10 \\
\hline 4Ts Scoring Group (n)
\end{tabular} & $10(8.7 \%)$ \\
\hline Low probability group & $88(76.5 \%)$ \\
\hline Intermediate probability group & $17(14.8 \%)$ \\
\hline High probability group & - \\
\hline PaGIA Positive & $2(2.3 \%)$ \\
\hline Low probability group & $4(23.5 \%)$ \\
\hline Intermediate probability group & $74(64.3 \%)$ \\
\hline High probability group & $17(14.8 \%)$ \\
\hline Surgery & $9(7.8 \%)$ \\
\hline Coronary artery bypass graft & $6(5,2 \%)$ \\
\hline Mitral valve replacement & $4(3.5 \%)$ \\
\hline Aortic valve replacement & $3(2.6 \%)$ \\
\hline Pouble valve replacement & $2(1.7 \%)$ \\
\hline $\begin{array}{l}\text { Coronary artery bypass graft }+ \\
\text { Mitral valve replacement }\end{array}$ & $\begin{array}{l}\text { Aortic valve replacement }+ \\
\text { Mitral valve replacement }\end{array}$
\end{tabular}

A statistically significant difference was obtained among low, intermediate, and high probability groups of ' $4 \mathrm{Ts}^{\prime}$ ' clinical scoring system when compared for the positivity of HPF4 antibodies, using the chi-square test $(p=0.01)$. The mean platelet count in patients who developed antibodies was $102 \times 10^{9} / \mathrm{L}$ and a minimum of $26 \times 10^{9} / \mathrm{L}$. Intheimmediate postoperative period, there was 
no event of thromboembolism reported in these patients. There were no statistically significant variables about genderbased demographics and patient's clinical data. led through '4Ts' were the intermediate probability of HIT group that is $76.5 \%$. The proportion of the patient in the intermediate group is almost similar to the cohort of Greifswald's ${ }^{12}$.

Table-III: Association of HIT with platelet count. As our data is not uniform, Wilcoxon Signed Rank test was used to assess the association of Heparin-induced thrombocytopenia with platelet change due to heparin therapy.

\begin{tabular}{l|c|c|c|c|c|c|c}
\hline & \multirow{2}{*}{ Median } & \multirow{2}{*}{ Mode } & \multirow{2}{*}{ IQR } & \multicolumn{3}{|c|}{ Percentiles } & \multirow{2}{*}{$\boldsymbol{*}$-value } \\
\cline { 5 - 8 } & & & & $\mathbf{2 5}$ & $\mathbf{5 0}$ & $\mathbf{7 5}$ & \\
\hline Pre-op platelets & 242 & 205 & 64 & 210 & 242 & 274 & - \\
\hline Post op Day 5-8 platelet count & 123 & 142 & 54 & 87 & 123 & 141 & - \\
\hline Change in platelet count & 124 & 111 & 57 & 98 & 124 & 155 & $<0.001$ \\
\hline
\end{tabular}

Table-IV: Comparison of clinical scoring group with Heparin-induced thrombocytopenia test.

\begin{tabular}{l|c|c|c|c}
\hline \multirow{2}{*}{ HIT Test } & \multicolumn{3}{|c|}{ Scoring Group } \\
\cline { 2 - 4 } & $\begin{array}{c}\text { Low Probability } \\
\text { Group }\end{array}$ & $\begin{array}{c}\text { Intermediate Probability } \\
\text { Group }\end{array}$ & $\begin{array}{c}\text { High Probability } \\
\text { Group }\end{array}$ & \multirow{2}{*}{$p$-value } \\
\hline Positive & - & $2(2.3 \%)$ & $4(23.5 \%)$ & \multirow{2}{*}{0.001} \\
\hline Negative & $10(100.0 \%)$ & $86(97.7 \%)$ & $13(76.5 \%)$ & \\
\hline Total & $10(8.7 \%)$ & $88(76.5 \%)$ & $17(14.8 \%)$ & \\
\hline
\end{tabular}

\section{DISCUSSION}

Cardiac surgery patients are at high risk of developing HIT because of platelet activation with the release of large amounts of PF4 as the vast majority of patients during surgery receive unfractionated heparin ${ }^{11}$. A study was done in Karachi $(n=100)$ reported serological evidence of HIT of $7 \%$ in postoperative cardiopulmonary bypass patients using the particle gel assay ${ }^{9}$.We report a total of $5.2 \%$ positive result in 115 patients in different cardiac surgeries, who were screened for HIT by combining the '4Ts' scoring system and particle gel assay.

There was no evidence of HIT antibodies found in $8.7 \%$ of the patient's population in the low pretest probability group as shown in tableIV. In these patients, HIT was excluded from the diagnosis. Such findings in the low-risk group are similar to the study results carried out in France ${ }^{8}$. The studies from Canada and Germany in 100 and 236 patients respectively also recorded the high NPV of 4 Ts score ${ }^{12}$. These observations endorse the '4Ts' score as a valid method for screening patients suspected of HIT in clinical settings therefore is recommended that assay for HIT antibodies are not required for low probability group ${ }^{12}$. In our study majority of patients enrol-
Only 17 out of 115 patients show a high score in 4Ts and lie in high probability group. This small percentage is explained by our clinical experience that several medications and certain infections can lead to thrombocytopenia. As a result score of ' $4 \mathrm{Ts}$ ' is rarely high in other common conditions causing thrombocytopenia unless there is occurrence or suspicion of recurrent thrombosis. We found a good correlation of 4Ts with the probability of HIT and the results were statistically significant $(p<0.001)$. The proportion of higher results in the high probability group is also observed in the study of Pouplard ${ }^{8}$. A recent study carried out by Lori-Ann Linkins also shows $36.6 \%$ confirmed HIT with a high probability of 4Ts score whereas the intermediate probability group showed $6.7 \%{ }^{13}$.

Different studies support our findings of increased risk of heparin-induced thrombocytopenia in high probability group ${ }^{14}$. It suggests that patients having a high score with 4Ts scoring system and positive immunoassay findings have a $100 \%$ posttest probability of HIT. Heparin should be withdrawal in this group for avoiding further platelet count fall and thrombosis ${ }^{15}$.

A patient undergoing cardiac surgery after 5 to 10 days may develop antibodies against 
PF4/heparin complex with the risk of HIT ranging from $1 \%$ to $3 \%{ }^{16}$. However in our study $5.2 \%$ had shown positive evidence of antibodies by IDPaGIA. There may be many reasons for this high frequency, the most common of which is that the methodology used for the detection of HIT is not the same as that used in different studies. We used particle gel immunoassay which is technically simple to perform. While the 14C-Serotonin release is a functional assay regarded as a gold standard for the detection of HIT because of its high sensitivity as well as specificity ${ }^{17}$. The IDPaGIA is a rapid gel immunoassay that is technically easy to perform but related to limited specificity and highly sensitive ${ }^{18}$. The data from various studies suggest that ID-PaGIA should be used in collaboration with a functional assay to confirm the diagnosis ${ }^{19}$. Some of the studies also used the combination of the clinical scoring system 4Ts with the particle gel assay for detecting heparin antibody to streng then the posttest probability of HIT8.

In our study, age and gender has not shown any significant association with HIT. A similar study supported our findings in which age and gender is not reported as a risk factor of HIT ${ }^{9}$.

The decline in platelet count reported in our study after postoperative day 5 to 8 is in concordance with the previously published literature ${ }^{8,9}$. The guidelines from the professional organizations also suggest that those taking heparin therapy regularly should have complete blood counts including platelet counts for monitoring the platelet count fall ${ }^{20}$.

Heparin-induced thrombocytopenia is often closely linked to venous and arterial thrombosis. Approximately $40-50 \%$ of patients develop thrombosis with thrombocytopenia alone ${ }^{21}$. In our study, 6 patients who develop antibodies against heparin/platelet factor 4 complex had mean platelet count $102 \times 10^{9} / \mathrm{L}$ and a minimum $26 \times 10^{9}$ / L but no patient had developed an episode of thrombosis in immediate post-operative time. It may be due to the small sample size of our study as well as the early discharge of patients.
Whereas in Pouplard et al study only one case of aortic thrombosis is reported in 305 patients having cardiac surgery 22 . It may be due to our population-related genetic variation. The risk factor for developing HIT related antibodies and thrombosis with FcyRIIa genotype was also reported in a study done at Duke University23.

\section{ACKNOWLEDGMENT}

My sincere thanks to my husband Dr. Yasir Nazir for his encouragement and insightful comments. I owe my deepest gratitude to my loving daughters Sara Yasir Nazir and Izzah Yasir Nazir for consistent moral support.

\section{RECOMMENDATION}

More prospective research is needed to determine the disease dimension using advanced means of testing such as $14 \mathrm{C}$ Serotonin release. The different polymorphisms associated with genetic variation in potential production of HIT associated antibodies must also require equal consideration for research.

\section{Disclosure}

This article is extracted from the research thesis of the corresponding author, which is mandatory for the fulfillment of the requirement of M.Phil.

\section{CONCLUSION}

Heparin-induced thrombocytopenia is a complication of unfractionated heparin inpatient undergoingcardiac surgery and a combination of pretest clinical scoring systems such as 4Ts combined with PaGIA an effective strategy to exclude HIT in patients. The patient with intermediate and high scoring with the 4Ts scoring system should be tested with PaGIA for the detection of antibodies against heparin/platelet factor 4 .

\section{CONFLICT OF INTEREST}

This study has no conflict of interest to be declared by any author.

\section{REFERENCES}

1. Maličev E. The use of flow cytometry in the diagnosis of heparin-induced thrombocytopenia (HIT). Transfus Med Rev 2020; 34(1): 34-41. 
2. Fathi M. Heparin-induced thrombocytopenia (HIT): Identification and treatment pathways. Glob Cardiol Sci Pract 2018; 2018(2): 1-15.

3. Roberts MK, Chaney S. Heparin-induced thrombocytopenia. J Nurse Pract 2018; 14(5): 402-08.

4. Pishko AM, Cuker A. Heparin-induced thrombocytopenia in cardiac surgery patients. Semin Thromb Hemost 2017; 43(7): 691-98.

5. Salter BS, Weiner MM, Trinh MA, Heller J, Evans AS, Adams $\mathrm{DH}$, et al. Heparin-induced thrombocytopenia: a comprehensive clinical review. J Am Coll Cardiol 2016; 67(21): 2519-32.

6. Arepally GM. Heparin-induced thrombocytopenia. Blood 2017; 129(21): 2864-72.

7. Brodard J, Alberio L, Angelillo-Scherrer A. Accuracy of heparininduced platelet aggregation test for the diagnosis of heparininduced thrombocytopenia. Thromb Res 2020; 185(1): 27-30.

8. Pouplard C, Gueret P, Fouassier M, Ternisien C, Trossaert M, Regina S, et al. Prospective evaluation of the '4Ts' score and particle gel immunoassay specific to heparin/PF4 for the diagnosis of heparininduced thrombocytopenia. J Thromb Haemost 2007; 5(7): 1373-79.

9. Ali N, Moiz B, Rehman Y, Salman M, Sami SA. The frequency of heparin induced thrombocytopenia in patients undergoing elective cardiac bypass surgeries. J Paki Med Assoc 2009; 59(6): 345-50.

10. Patriarcheas V, Pikoulas A, Kostis M, Charpidou A, Dimakakos E. Heparin-induced thrombocytopenia: pathophysiology, diagnosis and management. Cureus 2020; 12(3): e7385.

11. Pouplard C, Regina S, May MA, Gruel Y. Heparin-induced thrombocytopenia: a frequent complication after cardiac surgery. Arch Mal Coeur Vaiss 2007; 100(6-7): 563-68.

12. Lo G, Juhl D, Warkentin T, Sigouin C, Eichler P, Greinacher A. Evaluation of pretest clinical score (4T's) for the diagnosis of heparininduced thrombocytopenia in two clinical settings. J Thromb Haemost 2006; 4(4): 759-65.

13. Linkins LA, Bates SM, Lee AY, Heddle NM, Wang G, Warkentin TE. Combination of 4Ts score and PF4/H-PaGIA for diagnosis and management of heparin-induced thrombocytopenia: prospective cohort study. Blood 2015; 126(5): 597-603.

14. Nellen V, Sulzer I, Barizzi G, Lämmle B, Alberio L. Rapid exclusion or confirmation of heparin-induced thrombocytopenia: a single-center experience with 1,291 patients. Haematol 2012; 97(1): 89-97.

15. Watson H, Davidson S, Keeling D. Guidelines on the diagnosis and management of heparin induced thrombocytopenia. Br J Haematol 2012; 159(5): 528-33.

16. Linkins LA. Heparin induced thrombocytopenia. Bio Med J 2015; 350: g7566.

17. Warkentin TE. How I diagnose and manage HIT. Hematology Am Soc Hematol Educ Program 2011;2011(1):143-49.

18. Cuker A, Gimotty PA, Crowther MA, Warkentin TE. Predictive value of the $4 \mathrm{Ts}$ scoring system for heparin-induced thrombocytopenia: a systematic review and meta-analysis. Blood 2012; 120(20): 4160-67.

19. Szokol JW. Heparin-induced thrombocytopenia. Seminars in cardiothoracic and vascular anesthesia; 2010: SAGE Publications Sage CA: Los Angeles, CA.

20. Haughton B, Haughton J, Norman JG, Navid A, Allport K, Andrews $\mathrm{M}$, et al. Routine monitoring for heparin-induced thrombocytopenia following lower limb arthroplasty: Is it necessary? A prospective study in a UK district general hospital. Orthop Traumatol Surg Res 2019; 105(3): 497-501.

21. Levy JH, Tanaka KA, Hursting MJ. Reducing thrombotic complications in the perioperative setting: an update on heparin-induced thrombocytopenia. Anesth Analg2007; 105(3): 570-82.

22. Pouplard C, May MA, Regina S, Marchand M, Fusciardi J, Gruel Y. Changes in platelet count after cardiac surgery can effectively predict the development of pathogenic heparindependent antibodies. Br J Haematol 2005; 128(6): 837-41.

23. Arepally GM. Heparin-induced thrombocytopenia. Blood 2017; 129(21): 2864-72.

24. Warkentin T, Heddle N. Laboratory diagnosis of immune heparin-induced thrombocytopenia. Curr Hematol Rep 2003; 2(2): $148-57$. 